\title{
TOXICIDADE DE NATUNEEM SOBRE Tetranychus urticae Koch (Acari: Tetranychidae) E ÁCAROS PREDADORES DA FAMÍLIA PHYTOSEIIDAE
}

\author{
Toxicity of the natuneem over the Tetranychus urticae Koch (Acari: Tetranychidae) \\ and mites predators from the family Phytoseiidae
}

\author{
Hilda Maria Brito ${ }^{1}$, Manoel Guedes Corrêa Gondim Junior², José Vargas de Oliveira², \\ Cláudio Augusto Gomes da Câmara ${ }^{3}$
}

\begin{abstract}
RESUMO
A toxicidade de diferentes concentrações de Natuneem a Tetranychus urticae Koch e a dois ácaros predadores, Euseius alatus De Leon e Phytoseiulus macropilis (Banks), foi estudada. Foi avaliada a toxicidade sobre ovos, e o efeito residual e repelente, sobre adultos. O tratamento dos ovos consistiu na imersão em diluições de Natuneem por cinco segundos, e o efeito residual e repelente sobre adultos consistiu na imersão de discos de folhas de Canavalia ensiformes (L.) DC. também em diluições por cinco segundos. Natuneem foi repelente para T. urticae e E. alatus, quando testado nas concentrações de 0,25; 0,50 e 1,00\%, e exibiu efeito neutro para P. macropilis. A toxicidade de Natuneem a ovos e adultos foi maior para T. urticae comparada à toxicidade observada para os ácaros predadores. A fecundidade de T. urticae foi reduzida significativamente por Natuneem em todas as concentrações, enquanto para os ácaros predadores a redução foi significante apenas nas maiores concentrações. Natuneem, nas concentrações testadas, apresentou melhor ação sobre o ácaro-rajado e menor impacto para os ácaros predadores.
\end{abstract}

Termos para indexação: Azadiractina, controle, ácaro-rajado, fitoseídeos.

\begin{abstract}
The toxicity of the Natuneem at different concentrations for both Tetranychus urticae Koch and two predatory mites Euseius alatus De Leon and Phytoseiulus macropilis (Banks) were studied. The toxicity on eggs, and the residual and repellent effects on adults was evaluated. Egg treatment consisted on dipping eggs into Natuneem dilutions for five seconds; and residual and repellent effects for adults consisted on dipping leaf discs of Canavalia ensiformes (L.) DC. into the dilutions for five seconds. Natuneem was repellent for T. urticae and E. alatus at the concentrations $0.25,0.50$ and $1.0 \%$, and exhibited neutral effect on P. macropilis. The toxicity of Natuneem on eggs and adults was greater for $T$. urticae compared to the toxicity on predatory mites. The fecundity of $T$. urticae was reduced significantly by Natuneem in all concentration. On predatory mites significant reduction on its fecundity was found at the highest concentrations evaluated. Natuneem was performed better against the twospotted spider mite and exhibited relatively low impact against the predatory mites under the conditions studied.
\end{abstract}

Index terms: Azadirachtina, control, twospotted spider mite, phytoseiids.

(Recebido para publicação em 31 de janeiro de 2006 e aprovado em 12 de maio de 2006)

\section{INTRODUÇÃO}

Dentre os ácaros fitófagos, o ácaro rajado Tetranychus urticae Koch é considerado uma das mais importantes pragas agrícolas, infestando diversas culturas. Em várias plantas esse ácaro danifica a face inferior das folhas, causando inicialmente aparecimento de pontuações cloróticas, as quais posteriormente tornam-se manchas amareladas ou necróticas. Causa redução da área fotossintética, diminuição da produção e produtividade de inúmeras culturas anuais, fruteiras e hortaliças (FLECHTMANN, 1985). O seu controle é feito principalmente através de produtos fitossanitários, no entanto, o uso freqüente e indiscriminado destes produtos tem levado à presença de altos níveis de resíduos tóxicos nos alimentos, desenvolvimento de populações resistentes, intoxicação de mamíferos, destruição de organismos benéficos e poluição do ambiente (SATO et al., 2000).

Uma alternativa aos inseticidas sintéticos é a utilização de compostos naturais extraídos de plantas, conhecidos como metabólitos secundários, os quais já vêm sendo amplamente estudados e com resultados promissores no controle de ácaros fitófagos (GONÇALVES et al. 2001a; POTENZA et al., 1999a,b). Diversos derivados de plantas têm ação acaricida comprovada sobre $T$. urticae

'Engenheira Agrônoma - Universidade Federal Rural de Pernambuco/UFRPE - Departamento de Agronomia - Av. Dom Manoel de Medeiros s/n 52.171-900 - Recife, PE.

'Engenheiro Agrônomo, Doutor em Entomologia - Universidade Federal Rural de Pernambuco/UFRPE - Departamento de Agronomia- Av. Dom Manoel de Medeiros s/n - 52.171-900 - Recife, PE.

${ }^{3}$ Químico, Doutor em Química - Universidade Federal Rural de Pernambuco/UFRPE - Departamento de Agronomia - Av. Dom Manoel de Medeiros $\mathrm{s} / \mathrm{n}$ - 52.171-900 - Recife, PE. 
(CASTAGNOLI et al., 2000; El-GENGAIHI, 2000). Dentre essas plantas, destaca-se Azadirachta indica A. Juss, conhecida no Brasil por nim, que possui como principal composto ativo a azadiractina, um tetranortriterpenóide isolado das sementes (REMBOLD, 1989). Essa substância possui elevada ação inseticida e acaricida, baixíssima toxicidade ao homem e animais domésticos, seletividade aos inimigos naturais, além de não agredir o ambiente (MOURÃO et al., 2004).

$\mathrm{O}$ uso do nim como formulação pode ser na forma de pó seco, extrato aquoso e/ou orgânico (metanólico, etanólico, acetônico, clorofórmico, hexânico), óleo e pasta (SAXENA, 1989). Essa meliácea tem-se mostrado bastante promissora no manejo integrado de ácaros fitófagos, causando mortalidade, redução da fecundidade, deterrência, inviabilidade de formas imaturas e repelência (CASTIGLIONI et al., 2002; DIMETRY et al., 1993), apresentando, normalmente, seletividade para os inimigos naturais (SCHMUTTERER, 1997). A seletividade para ácaros predadores foi constatada em vários trabalhos com espécies da família Phytoseiidae, mostrando-se pouco tóxico a adultos e formas imaturas, e com baixo impacto na fecundidade (MANSOUR et al., 1993; MOMEN et al., 1997; SPOLLEN \& ISMAN, 1996).

Buscou-se com este trabalho determinar a perspectiva de uso da formulação Natuneem no controle do ácaro-rajado, através de testes laboratoriais, avaliandose o efeito repelente, toxicidade tópica sobre ovos e residual sobre adultos de T. urticae e dois ácaros predadores da família Phytoseiidae.

\section{MATERIAL E MÉTODOS}

Os experimentos foram conduzidos no Laboratório de Acarologia Agrícola do Departamento de Agronomia da Universidade Federal Rural de Pernambuco (UFRPE), a $27 \pm 0,5^{\circ} \mathrm{C}, 75 \pm 5 \%$ UR e fotofase de 12 horas.

Criação de T. urticae: O ácaro rajado foi criado em plantas de Canavalia ensiformes (L.) DC. cultivadas em casa-de-vegetação. Logo após a abertura completa do primeiro par de folhas cotiledonar, fez-se a infestação, com ácaros oriundos da criação do laboratório. As plantas foram trocadas semanalmente.

Criação de Predadores: Os predadores Phytoseiulus macropilis (Banks) e Euseius alatus De Leon foram criados em arenas de plástico com $17 \mathrm{~cm}$ de diâmetro e dois de altura. Utilizou-se T. urticae, como alimento, fornecido em folhas de $C$. ensiformes sobrepostas a discos de espuma de polietileno e papel filtro. A margem da folha foi contornada com algodão umedecido em água destilada para evitar a fuga dos ácaros. A folha foi trocada semanalmente. Na criação de E. alatus, também foi fornecido pólen de Ricinus communis L. e mel a 10\%, a cada três dias.

Obtenção do produto: A formulação Natuneem foi obtida no comércio da cidade do Recife-PE, sendo procedente da Natural Rural Ltda., Araraquara-SP.

Efeito repelente de Natuneem para $T$. urticae e ácaros predadores: Foram preparadas caldas com a formulação comercial de Natuneem nas concentrações de 0,$25 ; 0,50$ e 1,00\%. Discos de folha de C. ensiformes, com sete centímetros de diâmetro, tiveram um semicírculo imerso durante cinco segundos na calda, enquanto o outro semicírculo foi tratado com água destilada como testemunha, deixando-se uma área central não tratada de $0,7 \mathrm{~cm}$ de largura. A imersão foi realizada conforme metodologia descrita por Grafton-Cardwell \& Hoy (1983). Os discos foram imersos durante cinco segundos na calda, sob leve agitação, e colocados para secar à temperatura ambiente por 30 minutos. Em seguida, foram colocados para flutuar sobre água no interior de placas de Petri, fixados no centro da placa por um alfinete inserido em cola de silicone, conforme metodologia descrita por Reis \& Alves (1997), deixando-se um disco por placa.

$\mathrm{O}$ alimento de $T$. urticae foi o próprio disco de folha, enquanto para $E$. alatus o alimento oferecido foi pólen de $R$. communis, mel a $10 \%$ e massa de ovos de T. urticae, e para $P$. macropilis foi fornecida apenas massa de ovos de T. urticae, obtida conforme metodologia descrita por Bakker et al. (1992). A extração da massa de ovos consistiu na imersão de folhas de C. ensiformes infestadas com T. urticae em solução de água, hipoclorito de sódio a $2 \%$ e detergente líquido, e posterior filtragem em peneiras de 350; $700 \mathrm{e}$ 1000 mesh. Na área neutra do disco, foram liberadas 10 fêmeas adultas em início de postura, constituindo-se de uma repetição. Foram utilizadas oito repetições por tratamento.

Após 24 horas da instalação do experimento foram contados os ácaros que se encontravam na parte tratada com o produto e com água destilada. Os ácaros encontrados na área não tratada foram considerados, conforme a proximidade, na parte tratada com o produto ou com água destilada. Foi utilizado o teste do $\chi^{2}$ para comparação das concentrações do produto para cada espécie de ácaro, ao nível de 5\% de significância. A partir dos dados obtidos, foi calculado o Índice de Repelência (IR), conforme Kogan \& Goeden (1970), em que: IR= 2G/ $(\mathrm{G}+\mathrm{P})$, sendo $\mathrm{G}=$ Número de ácaros atraídos no semicírculo tratado com a formulação; $\mathrm{P}=$ Número de ácaros atraídos

Ciênc. agrotec., Lavras, v. 30, n. 4, p. 685-691, jul./ago., 2006 
no semicírculo tratado com água destilada; $\mathrm{DP}=$ Desvio padrão. Para a caracterização do efeito dos produtos foi utilizada a seguinte interpretação: 0 a 1-DP= repelente; 1 $\mathrm{DP}$ a $1+\mathrm{DP}=$ neutro; $1+\mathrm{DP}$ a $2=$ atraente.

Toxicidade de Natuneem a ovos e efeito residual sobre adultos de $T$. urticae e ácaros predadores: No estudo de toxicidade sobre ovos, infestaram-se discos de $C$. ensiformes de dois centímetros de diâmetro com 10 ovos de 0 a 24 h de idade. Em seguida, os discos foram imersos durante cinco segundos em caldas de Natuneem, nas concentrações de 0,$00 ; 0,25 ; 0,50$ e $1,00 \%$, conforme metodologia descrita por Grafton-Cardwell \& Hoy (1983), sendo $1,00 \%$ a concentração recomendada pelo fabricante. Posteriormente, foram secos em temperatura ambiente por 30 minutos e colocados para flutuar sobre água, no interior de placas de Petri, conforme metodologia descrita por Reis \& Alves (1997), deixando-se um disco por placa. A avaliação foi feita diariamente, observando-se a eclosão das larvas até sete dias após a instalação do experimento.

Para o estudo do efeito residual sobre adultos, foram transferidas 10 fêmeas adultas, em início de postura, para discos de $C$. ensiformes, após 30 minutos do tratamento. A avaliação da mortalidade e da oviposição das fêmeas foi feita diariamente, por três dias consecutivos.
O alimento dos ácaros foi o mesmo descrito para o estudo de repelência. Foram utilizadas oito repetições para cada tratamento. Os dados foram submetidos à análise de variância e as médias, comparadas pelo teste de Tukey em nível de 5\% de significância, utilizando-se o programa Sanest 3.0 (ZONTA et al., 1986).

\section{RESULTADOS E DISCUSSÃO}

A porcentagem de T. urticae e E. alatus repelidos por Natuneem variou de 70,0 a 98,8\%, enquanto os índices de repelência foram menores que o intervalo 1-DP (Tabela 1). Conseqüentemente, o produto foi considerado, nas dosagens testadas, como repelente para esses ácaros. Contudo, para $P$. macropilis, Natuneem repeliu de 47,5 a $53,8 \%$ dos ácaros, tendo os índices de repelência ficado dentro do intervalo de $1 \pm \mathrm{DP}$, sendo o produto considerado, nas dosagens testadas, como neutro.

A viabilidade de ovos de $T$. urticae tratados com Natuneem variou de 2,5 a 18,6\%, diferindo da testemunha com $97,5 \%$ (Tabela 2). Para E. alatus, essa viabilidade variou de 85,0 a $93,8 \%$, também diferindo da testemunha com $97,5 \%$, enquanto $P$. macropilis mostrou viabilidade de ovos variando de 90,0 a $97,5 \%$ e diferindo da testemunha com $100,0 \%$. Embora a viabilidade de ovos dos ácaros

TABELA 1 - Repelência de Natuneem a Tetranychus urticae e ácaros fitoseídeos em folhas de Canavalia ensiformes.

\begin{tabular}{ccccc}
\hline Espécie de ácaro & $\begin{array}{c}\text { Concentração } \\
\text { Natuneem }(\boldsymbol{\%})\end{array}$ & $\begin{array}{c}\text { Ácaros Repelidos } \\
\text { Natuneem }(\boldsymbol{\%})^{\mathbf{1}}\end{array}$ & IR $\pm \mathbf{D P}^{\mathbf{2}}$ & Classificação \\
\hline \multirow{2}{*}{ T. urticae } & 1,00 & $98,75 \mathrm{a}$ & $0,39 \pm 0,07$ & Repelente \\
& 0,50 & $96,25 \mathrm{a}$ & $0,44 \pm 0,11$ & Repelente \\
E. alatus & 0,25 & $97,50 \mathrm{a}$ & $0,41 \pm 0,10$ & Repelente \\
& 1,00 & $93,75 \mathrm{a}$ & $0,49 \pm 0,11$ & Repelente \\
& 0,50 & $80,00 \mathrm{a}$ & $0,69 \pm 0,12$ & Repelente \\
P. macropilis & 0,25 & $70,00 \mathrm{a}$ & $0,81 \pm 0,07$ & Repelente \\
& 1,00 & $53,75 \mathrm{a}$ & $0,97 \pm 0,07$ & Neutro \\
& 0,50 & $58,75 \mathrm{a}$ & $0,92 \pm 0,09$ & Neutro \\
& 0,25 & $47,50 \mathrm{a}$ & $1,02 \pm 0,10$ & Neutro
\end{tabular}

${ }^{1}$ Médias seguidas de mesma letra na coluna, dentro de cada espécie, não diferem entre si a 5\% de significância $\chi^{2}$ (Quiquadrado).

${ }^{2} \mathrm{IR}=$ índice de repelência $\pm \mathrm{DP}=$ desvio padrão. 
predadores, em todas as dosagens testadas, tenham diferido das respectivas testemunhas, a mesma foi sempre superior a $85,0 \%$, já a viabilidade de ovos do ácaro rajado na menor dosagem foi de apenas $18,6 \%$.

A porcentagem de mortalidade de T. urticae, alimentando-se de folhas de $C$. ensiformes tratadas com Natuneem variou de 40,0 a $56,0 \%$, diferindo da testemunha, a qual provocou mortalidade de $10,0 \%$. A mortalidade de $E$. alatus variou de 8,0 a $10,0 \%$, diferindo da testemunha, a qual não apresentou mortalidade. A porcentagem de mortalidade de P. macropilis variou de 4,0 a $11,0 \%$, diferindo da testemunha que apresentou mortalidade de $1 \%$. Para os predadores a mortalidade máxima foi de apenas $11,0 \%$, na maior concentração, enquanto para o ácaro rajado a menor mortalidade foi de 40,0\% (Tabela 2).

O número de ovos de T. urticae variou de 33,4 a 48,4 ovos por repetição, em folhas tratadas com Natuneem, durante 72 horas de postura, diferindo da testemunha, que apresentou 111,5 ovos em média por repetição. Para $E$. alatus o número de ovos na testemunha foi em média de 54,0 por repetição, diferindo dos demais tratamentos, que apresentaram de 42,8 a 50,0 ovos. Já $P$. macropilis apresentou 65,9 ovos na testemunha, enquanto nos demais tratamentos o número médio de ovos por repetição variou de 54,5 a 61,5 (Tabela 2).

TABELA 2 - Viabilidade de ovos (\%), mortalidade de fêmeas (\%) e número total de ovos (Média \pm EP) de Tetranychus urticae e ácaros fitoseídeos, em diferentes concentrações de Natuneem.

\begin{tabular}{|c|c|c|c|c|}
\hline \multirow{2}{*}{ Espécie de ácaro } & \multicolumn{4}{|c|}{ Concentração (\%) de Natuneem } \\
\hline & $\mathbf{0 , 0 0}$ & 0,25 & $\mathbf{0 , 5 0}$ & 1,00 \\
\hline & \multicolumn{4}{|c|}{ Viabilidade de ovos (\%) tratados por imersão } \\
\hline T. urticae & $97,5 \pm 0,16 \mathrm{aB}$ & $18,6 \pm 0,48 \mathrm{bC}$ & $7,5 \pm 0,41 \mathrm{cC}$ & $2,5 \pm 0,16 \mathrm{dC}$ \\
\hline E. alatus & $97,5 \pm 0,16 \mathrm{aB}$ & $93,8 \pm 0,42 \mathrm{bA}$ & $87,5 \pm 0,37 \mathrm{cB}$ & $85,0 \pm 0,46 \mathrm{~dB}$ \\
\hline P. macropilis & $100,0 \pm 0,00 \mathrm{aA}$ & $90,0 \pm 0,27 \mathrm{cB}$ & $90,0 \pm 0,25 \mathrm{cA}$ & $97,5 \pm 0,16 \mathrm{bA}$ \\
\hline
\end{tabular}

$\mathrm{CV}(\%)$
12,2

\begin{tabular}{lcccc}
\hline & \multicolumn{4}{c}{ Mortalidade (\%) de fêmeas em folhas de Canavalia ensiformes } \\
\cline { 2 - 5 } T. urticae & $10,0 \pm 3,30 \mathrm{dA}$ & $40,0 \pm 2,70 \mathrm{cA}$ & $51,0 \pm 3,00 \mathrm{bA}$ & $56,0 \pm 5,00 \mathrm{aA}$ \\
E. alatus & $0,0 \pm 0,00 \mathrm{cC}$ & $8,0 \pm 2,50 \mathrm{bB}$ & $8,0 \pm 2,50 \mathrm{bB}$ & $10,0 \pm 2,70 \mathrm{aC}$ \\
$P$. macropilis & $1,0 \pm 1,25 \mathrm{~dB}$ & $4,0 \pm 1,80 \mathrm{cC}$ & $8,0 \pm 2,50 \mathrm{bB}$ & $11,0 \pm 2,30 \mathrm{aB}$ \\
\hline
\end{tabular}

$\mathrm{CV}(\%)$
15,3

Número total de ovos por repetição durante 72 horas de confinamento

\begin{tabular}{lcccc}
\cline { 2 - 5 } T. urticae & $111,5 \pm 4,91 \mathrm{aA}$ & $48,4 \pm 1,28 \mathrm{bC}$ & $45,4 \pm 2,38 \mathrm{cC}$ & $33,4 \pm 1,83 \mathrm{dC}$ \\
E. alatus & $54,0 \pm 1,51 \mathrm{aC}$ & $50,0 \pm 2,24 \mathrm{bB}$ & $48,1 \pm 1,82 \mathrm{cB}$ & $42,8 \pm 1,62 \mathrm{~dB}$ \\
$P$. macropilis & $65,9 \pm 4,67 \mathrm{aB}$ & $61,5 \pm 2,56 \mathrm{bA}$ & $57,5 \pm 2,65 \mathrm{cA}$ & $54,5 \pm 3,45 \mathrm{dA}$ \\
\hline \multicolumn{1}{c}{ CV } & \multicolumn{3}{c}{13,3} \\
\hline
\end{tabular}

Médias seguidas de mesma letra, minúscula na linha e maiúscula na coluna, não diferem entre si pelo teste de Tukey a $5 \%$ de significância.

Ciênc. agrotec., Lavras, v. 30, n. 4, p. 685-691, jul./ago., 2006 
Diversos trabalhos têm demonstrado que a azadirachtina promove em ácaros repelência, mortalidade de formas imaturas e adultos, alteração no tempo de desenvolvimento, redução da fertilidade e longevidade (DIMETRY et al., 1993; GONÇALVES et al., 2001a,b; MANSOUR \& ASCHER, 1983; MANSOUR et al., 1987; SPOLLEN \& ISMAN, 1996). A formulação Natuneem, neste trabalho, foi mais tóxica a $T$. urticae, que aos ácaros predadores E. alatus e $P$. macropilis. Este fato pode ser verificado devido à maior mortalidade, menor viabilidade de ovos e fecundidade de T. urticae em relação aos predadores. Quanto ao efeito repelente, o produto apresentou resposta variável sendo repelente a $T$. urticae e E. alatus, entretanto mostrou-se neutro em relação a $P$. macropilis. Diversos autores têm demonstrado que a toxicidade de formulações à base de azadirachtina é normalmente maior para ácaros fitófagos que para ácaros predadores (CASTAGNOLI et al., 2002; MANSOUR et al., 1993, 1997; MOMEN, 1997).

Alguns autores investigaram formulações de nim (Neemgard e Neemix 45), com o mesmo teor de ingrediente ativo ( $4,5 \%$ de AZA), e constataram que ambas causaram elevada mortalidade a Tetranychus cinnabarinus (Boisduval.) e baixa mortalidade a Phytoseiulus persimilis Athias-Henriot (MANSOUR et al., 1997). Mansour \& Ascher (1983) atribuíram possíveis variações, entre as diversas formulações de nim encontradas no mercado, ao tipo de solvente extrator, constatando que os extratos orgânicos clorofórmico, n-butanólico, acetônico, pentânico e metanólico são mais eficazes que os aquosos, mesmo em concentração inferior a $0,5 \%$.

A toxicidade de azadirachtina aos ácaros pode ser alterada, sobretudo pelo solvente utilizado na extração deste tetranortriterpenóide, dosagem utilizada, parte da planta utilizada para extração e época e região de colheita (CASTIGLIONI et al., 2002; MANSOUR \& ASCHER, 1983; MANSOUR et al., 1987; MOURÃO et al., 2004).

A toxicidade da formulação Natuneem aos ácaros predadores $P$. macropilis e $E$. alatus pode ser atribuída aos mesmos mecanismos de resistência a inseticidas, tais como redução na penetração cuticular do produto, aumento na destoxificação metabólica e redução na sensibilidade do sítio de ação (OMOTO et al., 2000). Em fitoseídeos a resistência a inseticidas pode estar relacionada aos múltiplos mecanismos enzimáticos, através de enzimas como glutationa-S e transferase, que promovem a destoxificação (FOURNIER et al., 1987), e as esterases e monooxigenases, que diminuem a sensibilidade da acetilcolinesterase aos inseticidas (VIDAL \& KREITER, 1995).

\section{CONCLUSÕES}

A formulação comercial Natuneem, na dosagem de até $1 \%$ tem potencial para o uso no manejo integrado de Tetranychus urticae, apresentando excelente ação ovicida, assim como média ação tóxica sobre adultos. $\mathrm{O}$ produto também tem efeito na redução de fecundidade de Tetranychus urticae, além de se mostrar seletivo aos ácaros predadores Euseius alatus e Phytoseiulus macropilis.

\section{AGRADECIMENTOS}

À CAPES pela bolsa concedida ao primeiro autor, junto ao Programa de Pós-Graduação em Fitossanidade/ Entomologia da UFRPE.

\section{REFERÊNCIAS BIBLIOGRÁFICAS}

BAKKER, F.; GROVE, A.; BLUMEL, S.; CALIS, J.; OOMEN, P. Side-effect tests for phytoseiids and their rearing methods. IOBC/WPRS Bulletin, Montfavel, v. 15, n. 3, p. 61-81, 1992.

CASTAGNOLI, M.; ANGELI, G.; LIGUORI, M.; FORTI, D.; SIMONI, S. Side effects of botanical insecticides on predatory mite Amblyseius andersoni (Chant). Journal of Pest Science, Berlin, v. 75, p. 122-127, 2002.

CASTAGNOLI, M.; SIMONI, S.; GOGGIOLI, D. Attività biologica di sostanze vegetali nei confronti di Tetranychus urticae Koch (Acari: Tetranychidae) e del suo predatore Neoseiulus californicus (McGregor) (Acari: Phytoseiidae). Redia, Firenze, v. 83, p. 141-150, 2000.

CASTIGLIONI, E.; VENDRAMIM, J. D.; TAMAI, M. A. Evaluación del efecto tóxico de extractos acuosos y derivados de meliáceas sobre Tetranychus urticae (Koch) (Acari, Tetranychidae). Agrociência, México, v. 6, n. 2, p. 75-82, 2002.

DIMETRY, N. Z.; AMER, S. A. A.; REDA, A. S. Biological activity of two neem seed kernel extracts against the two-spotted spider mite Tetranychus urticae Koch. Journal of Applied Entomology, Hamburg, v. 116, p. 308312, 1993.

El-GENGAIHI, S.; DIMETRY, N. Z.; AMER, S. A. A.; MOHAMED, S. M. Acaricidal activity of lipoidal matter of different plant extracts against the two-spotted spider mite Tetranychus urticae Koch. Insect Science and its Application, Kenya, v. 20, n. 3, p. 191-194, 2000. 
FLECHTMANN, C. H. W. Ácaros de importância agrícola. São Paulo: Nobel, 1985. 189 p.

FOURNIER, D.; CUANY, A.; PRALAVORIO, M.; BRIDE, J. M.; BERGE, J. B. Analysis of methidathion resistance mechanisms in Phytoseiulus persimilis A.H. Pesticide Biochemistry and Physiology, Amsterdam, v. 28, p. 271278, 1987.

GONÇALVES, M. E. C.; OLIVEIRA, J. V.; BARROS, R.; TORRES, J. B. Efeito de extratos vegetais sobre estágios imaturos e fêmeas adultas de Mononychellus tanajoa (Bondar) (Acari:Tetranychidae). Neotropical Entomology, Londrina, v. 30, n. 2, p. 305-309, jun. 2001a.

GONÇALVES, M. E. C.; OLIVEIRA, J. V.; BARROS, R.; LIMA, M. P. L. Extratos aquosos de plantas e o comportamento do ácaro-verde-da-mandioca. Scientia Agricola, Piracicaba, v. 58, n. 3, p. 475-479, jul./set. 2001 b.

GRAFTON-CARDWELL, E. G.; HOY, M. A. Camparative toxicity of avermectin b1 to the predadtor Metaseiulus occidentalis (Nesbitt) (Acari: Phytoseiidae) and the spider mites Tetranychus urticae Koch and Panonychus ulmi (Koch) (Acari: Tetranychidae). Journal of Economic Entomology, Lanham, v. 76, p. 1216-1220, 1983.

KOGAN, M.; GOEDEN, R. D. The host-plant range of lema Trilineata daturaphila (Coleoptera: Chrysomelidae). Annals of Entomological Society of America, Lanham, v. 63, p. 1175-1180, 1970.

MANSOUR, F. A.; ASCHER, K. R. S. Effects of neem (Azadirachta indica) seed kernel extracts from different solvents on the carmine spider mite, Tetranychus cinnabarinus. Phytoparasitica, Israel, v. 11, n. 3/4, p. 177185, 1983.

MANSOUR, F. A.; ASCHER, K. R. S.; ABO-MOCH, F. Effects of Margosan-O ${ }^{\mathrm{TM}}$, Azatin ${ }^{\mathrm{TM}}$ and RD9-Repelin on spiders, and on predacious and phytophagous mites. Phytoparasitica, Israel, v. 21, n. 3, p. 205-211, 1993.

MANSOUR, F. A.; ASCHER, K. R. S.; ABO-MOCH, F. Effects of Neemgard on phytophagous and predacious mites and on spiders. Phytoparasitica, Israel, v. 25, n. 4, p. 333-336, 1997.
MANSOUR, F. A.; ASCHER, K. R. S.; OMARI, N. Effects of neem (Azadirachta indica) seed kernel extracts from different solvents on the predacious mite Phytoseiulus persimilis and the phutophagous mite Tetranychus cinnabarinus. Phytoparasitica, Israel, v. 15, p. 125-130, 1987.

MOMEN, F. M.; REDA, A. S.; AMER, S. A. A. Effect of neem Azal-F on Tetranychus urticae and three predacious mites of the family Phytoseiidae. Acta Phytopathologica et Entomologica Hungarica, Budapest, v. 32, n. 3/4, p. 355362, 1997.

MOURÃO, S. A.; SILVA, J. C. T.; GUEDES, R. N. C.; VENZON, M.; JHAM, G. N.; OLIVEIRA, C. L.; ZANUNCIO, J. C. Seletividade de extratos de nim (Azadirachta indica A. Juss.) ao ácaro predador Iphiseiodes zuluagai Denmark \& Muma (Acari: Phytoseiidae). Neotropical Entomology, Londrina, v. 33, n. 5, p. 613-617, set./out. 2004.

OMOTO, C.; ALVES, E. B.; RIBEIRO, P. C. Detecção e monitoramento da resistência de Brevipalpus phoenicis (Geijskes) (Acari: Tenuipalpidae) ao Dicofol. Anais da Sociedade Entomológica do Brasil, Londrina, v. 29, p. 757 764, 2000.

POTENZA, M. R.; TAKEMATSU, A. P.; BENEDICTO, L. H. Avaliação do controle de Tetranychus urticae (Koch, 1836) (Acari: Tetranychidae) através de extratos vegetais, em laboratório. Arquivos do Instituto Biológico, São Paulo, v. 66, p. 91-97, 1999b.

POTENZA, M. R.; TAKEMATSU, A. P.; SIVIERI, A. P.; SATO, M. E.; PASSEROTTI, C. M. Efeito acaricida de alguns extratos vegetais sobre Tetranychus urticae (Koch, 1836) (Acari: Tetranychidae) em laboratório. Arquivos do Instituto Biológico, São Paulo, v. 66, n. 1, p. 31-37, 1999a.

REIS, P. R.; ALVES, E. B. Criação do ácaro predador Iphiseiodes zuluagai Denmark \& Muma (Acari: Phytoseiidae) em laboratório. Anais da Sociedade Entomológica do Brasil, Londrina, v. 26, n. 3, p. 565-568, dez. 1997.

REMBOLD, H. Azadirachtins: their structure and mode of action. In: ARNASON, J. T.; PHILOGENE, B. J. R.; MORAND, P. Insecticides of plant origin. Washington: American Chemical Society, 1989. p. 150-163.

Ciênc. agrotec., Lavras, v. 30, n. 4, p. 685-691, jul./ago., 2006 
SATO, M. E.; PASSEROTTI, C. M.; TAKEMATSU, A. P.; SOUZA FILHO, M. F.; POTENZA, M. R.; SIVIERI, A. P. Resistência de Tetranychus urticae (Koch, 1836) a acaricidas, em pessegueiro (Prunus persica (L.) Batsch), em Paranapanema e Jundiaí-SP. Arquivos do Instituto Biológico, São Paulo, v. 67, n. 1, p. 117-123, jan./jun. 2000.

SAXENA, R. C. Inseticides from neem. In: ARNASON, J. T.; PHILOGENE, B. J. R.; MORAND, P. Insecticides of plant origin. Washington: American Chemical Society, 1989. p. 110-129.

SCHMUTTERER, H. Side-effects of neem (Azadirachta indica ) products on insect pathogens and natural enemies of spider mites and insects. Journal of Applied Entomology, Hamburg, v. 121, p. 121-128, 1997.
SPOLLEN, K. M.; ISMAN, M. B. Acute and sublethal effects of a neem insecticide on the commercial biological control agents Phytoseiulus persimilis and Amblyseius cucumeris (Acari: Phytoseiidae) and Aphidoletes aphidimyza (Diptera: Cecidomyiidae). Journal of Economic Entomology, Lanhan, v. 89, n. 6, p. 1379-1386, Dec. 1996.

VIDAL, C.; KREITER, S. Resistance to a range of insecticides in the predaceous mite Typhlodromus pyri (Acari: Phytoseiidae): inheritance and physiological mechanisms. Journal of Economic Entomology, Lanhan, v. 88, p. 1097-1105, 1995.

ZONTA, E. P.; SILVEIRA, P.; MACHADO, A. A. Sistema de análise estatística SANEST 3.0. Pelotas: UFPel, 1986. 399 p. 